\title{
Development and characterization of a nanomultilayer coating of pectin and chitosan - Evaluation of its gas barrier properties and application on 'Tommy Atkins' mangoes
}

\author{
Bartolomeu G. de S. Medeiros ${ }^{\mathrm{a}, \mathrm{b}}$, Ana C. Pinheiro ${ }^{\mathrm{a}}$, Maria G. Carneiro-da-Cunha ${ }^{\mathrm{b}}$, António A. Vicente ${ }^{\mathrm{a}, *}$ \\ ${ }^{a}$ IBB - Institute for Biotechnology and Bioengineering, Centre of Biological Engineering, Universidade do Minho, Campus de Gualtar, 4710-057 Braga, Portugal \\ ${ }^{\mathrm{b}}$ Departamento de Bioquímica, Laboratório de Imunopatologia Keizo Asami (LIKA), Universidade Federal de Pernambuco (UFPE), Av. Prof. Moraes Rego, s/n, \\ Cidade Universitária - CEP 50.670-420, Recife, PE, Brazil
}

\section{A R T I C L E I N F O}

\section{Article history:}

Received 26 July 2011

Received in revised form 21 November 2011

Accepted 16 December 2011

Available online 23 December 2011

\section{Keywords:}

Coatings

Films

Nanolayers

Pectin

Chitosan

Shelf-life

Mango

\begin{abstract}
A B S T R A C T
A nanomultilayer coating made of food-grade, bio-based materials (consisting of five nanolayers of pectin and chitosan) was produced. This coating was firstly characterized in terms of the water vapor, oxygen and carbon dioxide permeabilities; these parameters exhibited values of $0.019 \pm 0.005 \times 10^{-11}$, $0.069 \pm 0.066 \times 10^{-14}$ and $44.8 \pm 32 \times 10^{-14} \mathrm{~g} \mathrm{~m} /\left(\mathrm{Pa} \mathrm{s} \mathrm{m}^{2}\right)$, respectively, and are of the same order of magnitude of those found in other nanomultilayer systems. The nanomultilayer system was applied on whole 'Tommy Atkins' mangoes and the layers' adsorption was confirmed by changes in the contact angle of the coated fruits' skin. After $45 \mathrm{~d}$ of storage, uncoated mangoes presented a higher mass loss, higher total soluble solids and lower titratable acidity in comparison with coated mangoes. Uncoated mangoes had also a damaged and wrinkled appearance, showing evidence of microbial spoilage, and the flesh exhibited a slightly brownish color, in comparison with the coated mangoes. These results suggest a positive effect of the coating on gas flow reduction and on the consequent extension of the shelf-life of mangoes.
\end{abstract}

(c) 2011 Elsevier Ltd. All rights reserved.

\section{Introduction}

The works published so far dealing with the development of coatings composed of polysaccharides have brought several proposals of coatings to extend the shelf-life of fruits and vegetables, due to the selective permeability of these polymers to $\mathrm{O}_{2}$ and $\mathrm{CO}_{2}$. Pectin and chitosan are biodegradable, nontoxic biopolymers, which exhibit excellent biocompatibility and are of low cost (Shumilina and Shchipunov, 2002; Nunthanid et al., 2009). They present, among other characteristics, convenient gas barrier properties; however there is almost no information so far whether these properties remain the same at the nanoscale. Nanoscale materials could possibly improve the performance of edible films and coatings, introducing new properties, in particular the possibility of combining different layers with distinct functionalities (e.g. antimicrobial and antioxidant) and with improved and adequate gas barrier characteristics. Polysaccharide-based coatings can be used to control the internal atmosphere of fruits and retard their senescence (Nisperos-Carriedo, 1994), thus helping in their preservation, once they provide a partial barrier to moisture, $\mathrm{O}_{2}$ and $\mathrm{CO}_{2}$, also avoiding volatiles loss (Olivas and Barbosa-Cánovas,

\footnotetext{
* Corresponding author. Tel.: +351 253604419; fax: +351 253678986 .

E-mail address: avicente@deb.uminho.pt (A.A. Vicente).
}

2005). For instance, Elsabee et al. (2008) studied tomato packing in bags of transparent polypropylene film coated with non-nanoscale twelve alternating layers of chitosan and pectin, in view of a new concept of active packaging for fruit preservation.

Pectin is an anionic biopolymer soluble in water that shows low oxygen permeability $\left(\mathrm{O}_{2} \mathrm{P}\right)$ values (Thumula, 2006). It is one of the major structural polysaccharides of higher plant cells and consists on chains of linear regions of $(1 \rightarrow 4)$ - $\alpha$-D-galacturonosyl units and their methyl esters, interrupted in places by $(1 \rightarrow 2)$ - $\alpha$-L-rhamnopyranosyl units. Fractions of these rhamnopyranosyl residues are branch points for neutral sugar side chains of $(1 \rightarrow 5)$ - $\alpha$-L-arabinofuranosyl or ( $1 \rightarrow 4)$ - $\beta$-D-galactopyranosyl residues (Zsivánovits et al., 2005).

Chitosan, a natural cationic polysaccharide is formed by the $\mathrm{N}$-deacetylation of chitin (found e.g. in crustacean shells). It is a linear binary copolymer that consists of $\beta(1 \rightarrow 4)$-linked 2-acetoamido-2-deoxy- $\beta$-D-glucopyranose (Glc-NAc; A-unit) and 2-amino-2-deoxy- $\beta$-D-gluco-pyranose (GlcN; D-unit) (Kumar et al., 2004). It exhibits interesting gas barrier properties and is often used for food packaging applications (Srinivasa et al., 2002). In view of chitosan qualities, films and coatings with chitosan have been used as packaging material for foods (Zhang and Quantick, 1997; Choi et al., 2002; Park and Zhao, 2004; Suyatma et al., 2005; Wu et al., 2005; Chien et al., 2007; Ribeiro et al., 2007; Tripathi et al., 2008). 
The ripening of climacteric fruits such as mango is related to ethylene synthesis and is proportional to $\mathrm{O}_{2}$ concentration. A lower $\mathrm{O}_{2}$ concentration represents a lower ethylene concentration resulting in a slower ripening (Baldwin et al., 1999). Therefore, the respiration rate is inversely proportional to the fruit's lifetime (Ravindra and Goswami, 2008). However, deterioration caused by yeasts, and especially by bacteria, may still occur at very low concentrations of $\mathrm{O}_{2}$ and elevated $\mathrm{CO}_{2}$ levels (Westall and Filtenborg, 1998). The water loss is another factor affecting the quality of fruits (Rojas-Grau et al., 2008), reducing the shelf-life due not only to water loss alone but also due to enzymatic browning and deterioration of texture. 'Tommy Atkins' mango (Mangifera indica L.) is one of the most consumed tropical fruits and the second most planted cultivar worldwide (Evangelista et al., 2002). It is preferentially consumed in fresh however, after being picked, an intense respiration takes place which boosts its deterioration (Fonseca, 1999).

Being the follow up of the works from Carneiro-da-Cunha et al. (2010) and Medeiros et al. (in press), the aim of this work was to develop and characterize the properties of a nanomultilayer coating, obtained by electrostatic layer-by-layer (LbL) self-assembly, assembled directly on the fruit skin with five alternate layers of pectin and chitosan, and to evaluate its gas flow barrier properties affecting the shelf-life of 'Tommy Atkins' mango. A period of analysis of $45 \mathrm{~d}$ was chosen, taking into account that after picking mangoes are transported mostly by ship from South America to Europe, which implies a long period of storage until consumption that was simulated in this work.

\section{Materials and methods}

\subsection{Materials}

Polyethylene terephthalate (PET) films were obtained from Canson (Annonay Cedex, France). High methoxy pectin (Pec) (degree of methyl esterification $=72.3 \%$ ) was obtained from CP Kelco (Atlanta, USA) and chitosan (Ch) was purchased from Aqua Premier Co. Ltd. (Chonburi, Thailand). 1,6 Hexanediamine (98\%) was obtained from Aldrich (Steinheim, Germany) and propanol (99.8\%) obtained from Sigma-Aldrich (St. Louis, USA). Lactic acid (90\%), sodium hydroxide and hydrochloric acid were obtained from Merck (Darmstadt, Germany). Semi-ripe (titratable acidity $=0.80 \pm$ $0.01 \%$ ); total soluble solids $=11.5 \pm 0.05^{\circ}$ Brix) 'Tommy Atkins' mangoes from Saint Francisco Valley (Brazil) were purchased from Pingo Doce (Braga, Portugal). Care was taken to ensure that all the fruits were from the same lot.

\subsection{Preparation of a nanomultilayer coating on PET}

In order to allow the determination of the gas permeabilities of the nanomultilayer coating, the polysaccharide layers were assembled on a transparent PET film that was firstly aminolyzed/charged (A/C PET), according to Fu et al. (2005). The surface of the PET film was treated by the chemical aminolysis method using 1,6-hexanediamine to insert amino groups, through a nucleophilic attack of the nitrogen to the carbonium center of the carbonyl ester. These random attacks on the carbonyl groups of the molecule of the polymer present on the surface groups of the film generate and remove short chains. The aminolyzed PET was subsequently treated with $\mathrm{HCl}$ to charge positively the surface of the substrate.

Both solutions of pectin and chitosan were separately prepared at a concentration of $0.2 \%(\mathrm{w} / \mathrm{v})$ under agitation for $2 \mathrm{~h}$ at room temperature $\left(25^{\circ} \mathrm{C}\right)$. The pectin solution was prepared in distilled water and the chitosan solution in $1.0 \%(\mathrm{v} / \mathrm{v})$ lactic acid solution.
The $\mathrm{pH}$ of solutions was adjusted at 7.0 with sodium hydroxide and 3.0 with lactic acid, respectively.

A/C PET pieces $(0.8 \times 5.0 \mathrm{~cm}$ and circular pieces of $5.0 \mathrm{~cm}$ diameter) were immersed into pectin solution $(\mathrm{pH} 7.0)$ for $15 \mathrm{~min}$ and subsequently rinsed with distilled water with $\mathrm{pH}$ 7.0 and dried with a nitrogen flow. Afterwards, the films adsorbed with the first layer were immersed into the chitosan solution $(\mathrm{pH}$ 3.0) for $15 \mathrm{~min}$ and subsequently rinsed with distilled water with $\mathrm{pH} 3.0$ and dried again with a nitrogen flow. This process was repeated until the alternate deposition of a total of five layers was achieved.

\subsection{Characterization of the nanomultilayer coating on PET}

\subsubsection{Fourier transform infrared spectroscopy (FTIR)}

To confirm the presence of amino groups on PET pieces, Fourier Transform Infrared Spectroscopy (FTIR) analyses were carried out with a Perkin Elmer 16 PC spectrometer (Perkin Elmer Boston USA). Five alternated polysaccharide layers (Pec-Ch-Pec-Ch-Pec) were subsequently and sequentially adsorbed on the A/C PET film.

\subsubsection{Zeta potential}

Zeta potential of both solutions was determined by dynamic light scattering (DLS) (Zetasizer, Worcestershire, Malvern Instruments, UK), to confirm their opposite charge. Measurements were taken in triplicate, with three readings for each of them. Pectin has a constant of dissociation (pKa) ranging between 3 and 4 (Sriamornsak et al., 2007) and chitosan around 6.5-6.6 (Strand et al., 2001). Taking this into account and to ensure that the interaction between the polyelectrolyte solutions and the $\mathrm{A} / \mathrm{C}$ PET surface would be strong enough, the $\mathrm{pH}$ values of polyelectrolyte solutions were previously adjusted to obtain the opposite adequate charges.

\subsubsection{UV/Vis absorbance}

To follow the multilayer film assembly, a UV-Vis spectrophotometer (Jasco 560, Gross-Umstadt, Germany) was used to measure the absorbance after the addition of each layer. The absorbance was measured at $266 \mathrm{~nm}$ on the dried films. Three replications of the measurements were taken.

\subsubsection{Contact angle analysis}

Also after the addition of each of the layers, the surface contact angle was determined by the sessile drop method (Newman and Kwok, 1999), with a contact angle meter (OCA 20, Dataphysics, Filderstadt, Germany). Measurements were made at $15 \mathrm{~s}$ and for each type of surface three films samples were used. Ten replicates of contact angle measurements were carried out at $22.2 \pm 0.4^{\circ} \mathrm{C}$.

\subsubsection{Scanning electron microscopy (SEM) analysis}

The surface morphology of the multilayer film as well as the thickness of each of the five nanolayers were examined using a scanning electron microscope (Nova 130 NanoSEM 200, Netherlands) with an accelerating voltage from 10 to $15 \mathrm{kV}$.

\subsubsection{Water vapor permeability (WVP)}

The water vapor permeability of the A/C PET $\left(\mathrm{WVP}_{a}\right)$ and of the $\mathrm{A} / \mathrm{C}$ PET +5 nanolayers (A/C PET-Pec-Ch-Pec-Ch-Pec) $\left(\mathrm{WVP}_{t}\right)$ was determined gravimetrically (Eq. (1)) based on ASTM E96-92 method (McHugh et al., 1993). The films were sealed on the top of a permeation cell containing $55 \mathrm{ml}$ of distilled water $(100 \% \mathrm{RH}, 2337 \mathrm{~Pa}$ vapor pressure at $20^{\circ} \mathrm{C}$ ). The cells were placed in a desiccator at $20{ }^{\circ} \mathrm{C}$ and $0 \% \mathrm{RH}$ (0 Pa water vapor pressure), containing silica gel. The cells were weighed during $10 \mathrm{~h}$ at intervals of $2 \mathrm{~h}$. The slope of weight loss versus time was achieved by linear regression. Three replicates were obtained for each film and WVP of the 
polysaccharide nanomultilayer (Pec-Ch-Pec-Ch-Pec) was determined by the following equation:

$\mathrm{WVP}_{b}=\frac{L_{b}}{\left(\frac{L_{t}}{\mathrm{WVP}_{t}}\right)-\left(\frac{L_{a}}{\mathrm{WVP}_{a}}\right)}$

where the indices $a, b$ and $t$ correspond to: (i) the A/C PET, (ii) the polysaccharide nanomultilayer (Pec-Ch-Pec-Ch-Pec) and (iii) the obtained multilayer film (A/C PET-Pec-Ch-Pec-Ch-Pec). $L_{a}$ corresponds to the thickness of the A/C PET films and $L_{b}$ the thickness of the five layers that were measured by digital micrometer (Mitutoyo, Kanagawa, Japan) and SEM, respectively.

\subsubsection{Oxygen and carbon dioxide permeabilities}

Oxygen permeability $\left(\mathrm{O}_{2} \mathrm{P}\right)$ and carbon dioxide permeability $\left(\mathrm{CO}_{2} \mathrm{P}\right)$ were determined based on the ASTM D 3985-02 (2002) method. The $\mathrm{A} / \mathrm{C}$ PET and the $\mathrm{A} / \mathrm{C}$ PET +5 nanolayers (A/C PET$\mathrm{Pec}-\mathrm{Ch}-\mathrm{Pec}-\mathrm{Ch}-\mathrm{Pec}$ ) pieces were placed between two chambers, each one with two channels to the exterior. In the lower chamber, $\mathrm{O}_{2}$ or $\mathrm{CO}_{2}$, were supplied at a controlled flow rate to keep the pressure constant in the compartment. The upper chamber was purged by a stream of nitrogen, also at a controlled flow. The nitrogen acted as a carrier for the $\mathrm{O}_{2}$ or $\mathrm{CO}_{2}$ coming from the lower chamber through the film. The flows of the two chambers were connected to manometers to ensure the equality of pressures between both compartments at $1 \mathrm{~atm}$. As the $\mathrm{O}_{2}$ or $\mathrm{CO}_{2}$ were carried continuously by the nitrogen flow, it was considered that the partial pressure of $\mathrm{O}_{2}$ or $\mathrm{CO}_{2}$ in the upper compartments is null, therefore $\Delta \mathrm{P}$ is equal to $1 \mathrm{~atm} . \mathrm{O}_{2} \mathrm{P}$ was determined from the measurements of $\mathrm{O}_{2}$ concentration in the nitrogen flow leaving the chamber with an $\mathrm{O}_{2}$ sensor installed on-line. $\mathrm{CO}_{2} \mathrm{P}$ was determined from the measurements of $\mathrm{CO}_{2}$ concentration in a gas chromatograph (Chrompack 9001, Middelburg, Netherlands). This procedure was performed with $\mathrm{A} / \mathrm{C}$ PET as reference (thus obtaining the values of $\mathrm{O}_{2} \mathrm{P}_{a}$ and $\mathrm{CO}_{2} \mathrm{P}_{a}$ ) and with the A/C PET +5 nanolayers (A/C PET-Pec-Ch-PecCh-Pec) (thus obtaining the values of $\mathrm{O}_{2} \mathrm{P}_{t}$ and $\mathrm{CO}_{2} \mathrm{P}_{t}$ ). Three replicates were obtained for each sample. The $\mathrm{O}_{2} \mathrm{P}$ and $\mathrm{CO}_{2} \mathrm{P}$ for the five layers (Pec-Ch-Pec-Ch-Pec) were determined with an equation similar to Eq. (1) where $\mathrm{WVP}_{b}, \mathrm{WVP}_{t}$ and $\mathrm{WVP}_{a}$ were changed by $\mathrm{O}_{2} \mathrm{P}_{b}, \mathrm{O}_{2} \mathrm{P}_{t}$ and $\mathrm{O}_{2} \mathrm{P}_{a}$ for $\mathrm{O}_{2} \mathrm{P}_{b}$ calculation, and $\mathrm{CO}_{2} \mathrm{P}_{b}, \mathrm{CO}_{2} \mathrm{P}_{t}$ and $\mathrm{CO}_{2} \mathrm{P}_{a}$ for $\mathrm{CO}_{2} \mathrm{P}_{b}$, respectively.

\subsection{Mangoes coating and physico-chemical analyses}

\subsubsection{Mangoes coating}

Thirty-six 'Tommy Atkins' mangoes at a semi-ripe stage (as previously indicated) with similar size, absence of damages and apparent absence of fungal infection were washed with water, left to dry and randomly divided into two groups (one control and one test group) of eighteen mangoes each. Coating solutions (pectin and chitosan) were applied on the test group in a similar way as done on A/C PET surface. The immersion time into each polyelectrolyte solution was of $15 \mathrm{~min}$. The immersion time for the control group was the same, but distilled water with the same $\mathrm{pH}$ of pectin (Pec) or chitosan $(\mathrm{Ch})$ solutions was used instead of the polyelectrolyte solutions. Afterwards, all mangoes were placed into plastic boxes and stored at $4{ }^{\circ} \mathrm{C}$ and $93 \% \mathrm{RH}$ (in a room at controlled temperature and relative humidity). These conditions are not generally followed at commercial level; however they were chosen as mangoes are chilling-sensitive and therefore the nanomultilayer coating would be tested under strengthened stress conditions. It must be emphasized that the aim of this work was not to perform a full post-harvest shelf-life analysis of the mangoes; the main idea was to provide a preliminary demonstration of the potential benefits of the nanomultilayer coating developed here. All physicochemical analyses were run in triplicate.

\subsubsection{Physico-chemical analyses}

2.4.2.1. Contact angles analysis. Contact angles on mango surface were determined using the sessile drop method. Briefly: a $2 \mu \mathrm{l}$ droplet of ultra pure water was placed on the surface of each piece of mango peel with a $500 \mu \mathrm{l}$ syringe (Hamilton, Bonaduz, Switzerland) with a needle of $0.75 \mathrm{~mm}$ diameter. The measurements were taken after $15 \mathrm{~s}$; three samples were used with ten determinations on each sample, at the temperature of $22.3 \pm 0.6^{\circ} \mathrm{C}$.

2.4.2.2. Mass loss. Mass loss was evaluated with an analytical balance (METTLER AE200, Mettler-Toledo, Giesen, Germany). All mangoes were individually weighed at the beginning of the work and during the experimental storage time. The mass loss $(W)$ was expressed as $W(\%)=\left(m_{i}-m_{t}\right) / m_{i} \times 100$, where $m_{i}$ is the initial weight and $m_{t}$ is the weight at time $t$.

2.4.2.3. Total soluble solids (TSS). Mango samples were peeled off and cut lengthwise to remove the stones. With a domestic extractor (Moulinex Mx type 664, Spain) juice samples were collected in sterilized jars in aseptic conditions. The total soluble solids (TSS) were determined on the juice using a refractometer (Schmidt + Haensch, GmbH and Co. series No. 4008, Berlin, Germany) with direct readings in ${ }^{\circ}$ Brix scale.

2.4.2.4. Titratable acidity (TA). Titratable acidity was determined by titrating $10 \mathrm{~g}$ of liquefied mango with $100 \mathrm{ml}$ of distilled water with $0.1 \mathrm{M} \mathrm{NaOH}$ (Instituto Adolfo Lutz, 1985). The results were expressed as \% (w/w).

\subsection{Statistical analyses}

The statistical analyses were carried out using analysis of variance (ANOVA), Tukey mean comparison test $(p<0.05)$ and linear regression analysis (SigmaStat, trial version, 2003, USA).

\section{Results and discussion}

\subsection{Evaluation of the nanomultilayer coating on PET}

\subsubsection{Aminolysis of PET}

The aminolysis of PET was confirmed by the presence of two peaks, located at 1645 and at $1560 \mathrm{~cm}^{-1}$, in the A/C PET FTIR spectra, which are not observed in the original PET samples (data not shown). Similar results were reported by Medeiros et al. (in press). These two peaks are related with the introduction of amide groups, meaning that the PET was successfully aminolyzed and has now a positive charge on its surface.

\subsubsection{Zeta potential}

The opposite charges of these two solutions were confirmed by dynamic light scattering with values of $-45.23 \pm 1.87 \mathrm{mV}$ at $\mathrm{pH} 7.0$ for pectin and $+43.17 \pm 3.03 \mathrm{mV}$ at $\mathrm{pH} 3.0$ for chitosan.

\subsubsection{UV-Vis absorbance}

The successive deposition of layers was followed measuring the increase of absorbance at $266 \mathrm{~nm}$ (Fig. 1), the wavelength at which the highest absorbance peak was found.

The significant increase $(p<0.05)$ of absorbance illustrated in Fig. 1 confirms the successful assembly of the nanomultilayer coating on $\mathrm{A} / \mathrm{C}$ PET and means that the polyelectrolyte solutions were successively adsorbed due to the electrostatic interactions of their opposite charges. The increase in the absorbance due to the layers deposition is in agreement with other works where the deposition through layer-by-layer technique was characterized by UV-Vis 


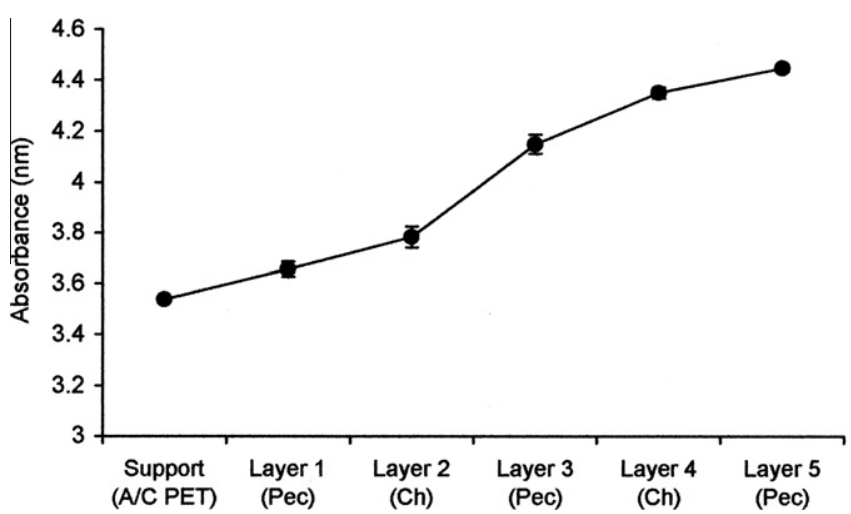

Fig. 1. UV-Vis spectroscopy analysis at $\lambda=266 \mathrm{~nm}$ of $\mathrm{A} / \mathrm{C}$ PET and of the five successive layers containing pectin $(\mathrm{Pec})$ and chitosan $(\mathrm{Ch})$. Each data point is the average of three determinations and the error bars show the standard deviation.

spectroscopy (Fu et al., 2005; Carneiro-da-Cunha et al., 2010; Medeiros et al., in press).

\subsubsection{Contact angle}

The original PET presented a contact angle of $80.04 \pm 1.48^{\circ}$, confirming its hydrophobicity, while A/C PET showed a significantly $(p<0.05)$ lower value of $75.35 \pm 2.67^{\circ}$ (Fig. 2$)$. From this behavior, it can be assured that the aminolysis of PET surface was successful, in agreement with the results from FTIR analyses. Working with a polyurethane (PU) substrate aminolyzed in $0.06 \mathrm{~g} \mathrm{ml}^{-1} 1,6$-hexanediamine/propanol solution at $37^{\circ} \mathrm{C}$ for $4,10,20,60$ and $120 \mathrm{~min}$, Zhu et al. (2004) found the best aminolysis degree for an aminolyzation time of $120 \mathrm{~min}$ and the sessile drop method showed contact angles of $69.30 \pm 0.2^{\circ}$ and $63.90 \pm 1.0^{\circ}$ for the original and aminolyzed PU, respectively. The differences found between the aminolyzed PET and the aminolyzed PU $\left(75.35^{\circ}\right.$ and $63.90^{\circ}$, respectively) show that the aminolyzed PET used in our work is more hydrophobic. Xu et al. (2008) worked with a multilayer film of alginate and chitosan and they also report contact angles of a similar magnitude to that of our work for PET and aminolized PET. However, the adsorption of the polyanion performed by these authors was made with poly(ethylenimine) (PEI) while in this work it was used 1,6-hexanediamine.

High values of the contact angle are typical of a hydrophobic surface, while low values are characteristic of a hydrophilic surface

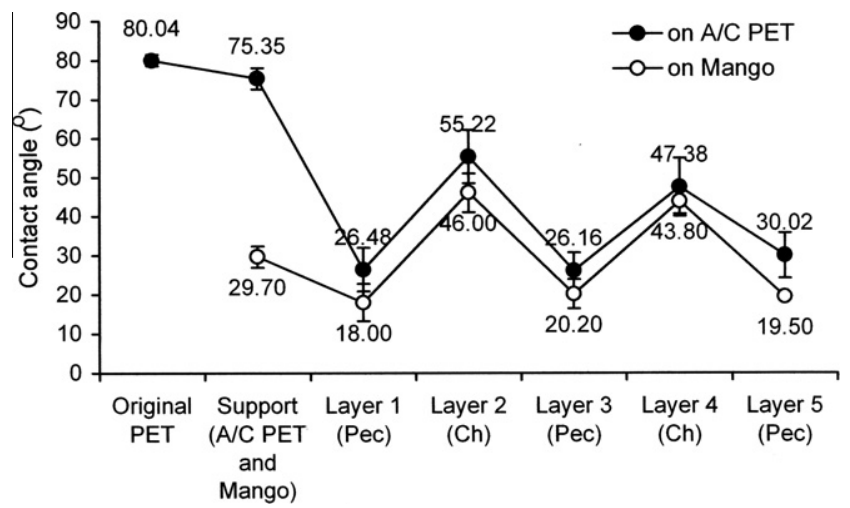

Fig. 2. Contact angles measured after $15 \mathrm{~s}$ of droplet application. Results "on $\mathrm{A} / \mathrm{C}$ PET" correspond to contact angles measured on Original PET, on A/C PET and on the five successive layers containing pectin (Pec) and chitosan (Ch). Results "on Mango" correspond to contact angles measured on mango surface and on the five successive layers applied on mango surface containing pectin (Pec) and chitosan (Ch). Each data point is the average of thirty measurements and the error bars show the standard deviation.
(Morra and Cassinelli, 1996). In this work the angles with significantly $(p<0.05)$ smaller magnitude were obtained for the layers assembled at $\mathrm{pH} 7.0(\mathrm{Pec})$ and high contact angles were obtained for the layers assembled at $\mathrm{pH} 3.0(\mathrm{Ch})$. The evolution of the magnitude of contact angles shows the alternate deposition of Pec and $\mathrm{Ch}$, confirming that the film was progressively assembled by alternate deposition of these two polyelectrolytes (Fig. 2). Fu et al. (2005) worked on a multilayer film of heparin and chitosan assembled on PET aminolyzed with 1,6-hexanediamine and $\mathrm{Xu}$ et al. (2008) on a multilayer film of alginate and chitosan assembled on PET aminolyzed with poly(ethylenimine) (PEI) and they also found contact angles for chitosan of similar magnitude and with the same behavior.

\subsubsection{Scanning electron microscopy (SEM)}

Scanning electron microscopy (SEM) image of the nanomultilayer coating can be seen in Fig. 3. SEM allowed estimating the thicknesses of the successive pectin and chitosan layers as being $52.8,53.7,59.4,52.8$ and $48.1 \mathrm{~nm}$, respectively, thus resulting in an estimated total thickness value (five layers) of $266 \mathrm{~nm}$. After the deposition of the five successive layers, the outmost surface (Pec layer) of the multilayer A/C PET film exhibited a rough surface (SEM image not shown). Fu et al. (2005), working with heparin and chitosan layers, concluded that the assembly $\mathrm{pH}$ has influence on the surface roughness of multilayers and the layers assembled at $\mathrm{pH}$ of 6.0 have rougher surfaces while those assembled at $\mathrm{pH} 3.8$ have smoother ones. Many chains from the underlying layer may penetrate into the surface of the outmost layer and a multilayer surface may become more hydrophilic or more hydrophobic due to the level of the penetration of chains from the underlying layer into the outmost layer. Yoo et al. (1998), investigating the influence of $\mathrm{pH}$ of dipping solutions on the surface wettability of a multilayer system composed of two weak polyelectrolytes [poly(acrilic acid) and poly(allylamine)], reported that in the weak polyelectrolytes, the highly charged polymer chains tended to be absorbed as thin layers with flat chains conformation, while the less charged polymer chains tended to be absorbed as thicker, loppier-type structures. For the systems containing weak polyelectrolytes

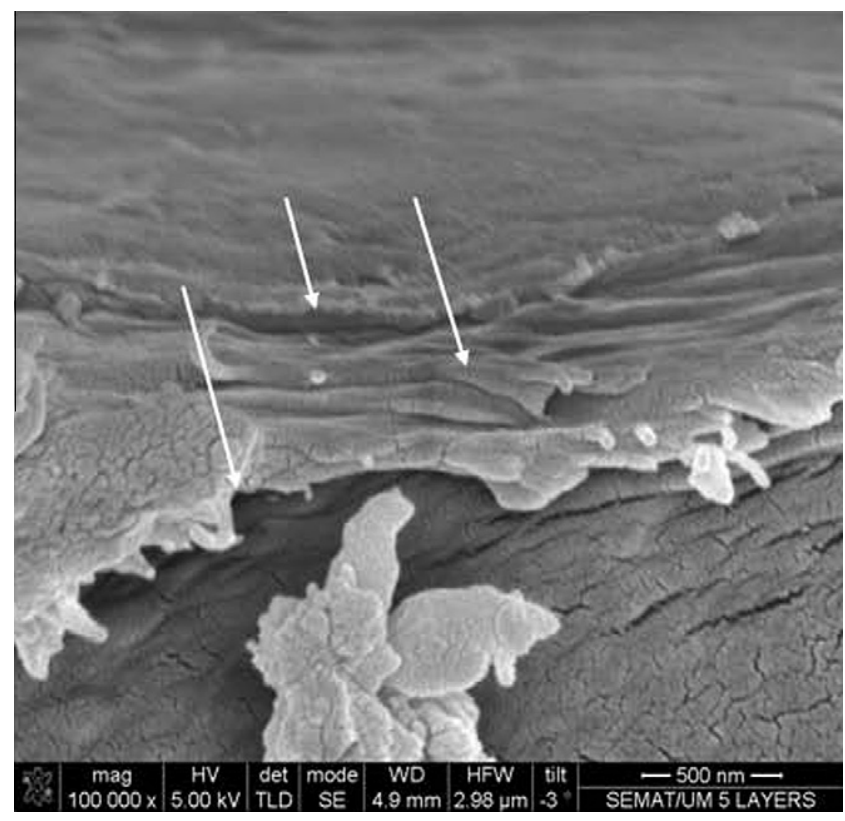

Fig. 3. Scanning electron microscopy cross-section image of the nanolayered coating (scale bar $500 \mathrm{~nm}$ ). The arrows indicate individual nanolayers, presumably of the two materials used for their construction (chitosan and pectin). 
(pectin and chitosan), the interaction between oppositely charged polyelectrolytes show a strong dependence on $\mathrm{pH}$ and the thickness of an individual layer is dependent on biopolymer concentration and is particularly marked for pectin and weaker for chitosan (Marudova et al., 2005). In this work, both polyelectrolyte solutions of pectin and chitosan were separately prepared at a concentration of $0.2 \%(\mathrm{w} / \mathrm{v})$. The adsorption of pectin solution as a thin layer provided by the highly charged polymer $(\mathrm{Pec})$ chains and by its hydrophilicity, may have been counterbalanced by the high $\mathrm{pH} 7.0$ of the corresponding polymer solution and by the dependence on the concentration of the biopolymer. In turn, the adsorption of chitosan solution as a thicker layer than that of pectin solution was possibly due to its hydrophobicity although it was counterbalanced by the highly charged polymer chains and the low pH value of 3.0 of the polyelectrolyte solution. These circumstances, and depending on the level of the penetration of chains from one layer into the other layer, may have contributed to the formation of layers with rather homogeneous.

Besides, hydration is a critical parameter for polyelectrolyte multilayer films, impacting film thickness, swellability and diffusion of the film's components. Film hydration can vary during film assembly. The film swelling properties (i.e. their ability to change volume and thickness as the environmental conditions are changed, such as $\mathrm{pH}$, ionic strength, hydration) has been found to be depend on assembly conditions. When the films are built by alternate dipping into the polyelectrolyte solutions followed by intermediate drying steps, the swelling of the film between the dried and wet states can be very significant (Crouzier et al., 2010).

In the process of layers deposition, the A/C PET support was dipped into the polyelectrolyte solutions and both sides of support were coated with the five layers. Thus, the total thickness of layers on both sides, can be estimated as $266 \mathrm{~nm} \times 2=532 \mathrm{~nm}=$ $5.32 \times 10^{-7} \mathrm{~m}$. Taking into account that the thickness of A/C PET support, measured by a digital micrometer, was $0.103 \mathrm{~mm}=$ $1.03 \times 10^{-4} \mathrm{~m}$, the total thickness of the coated support was $5.32 \times 10^{-7} \mathrm{~m}+1.03 \times 10^{-4} \mathrm{~m}=1.03532 \times 10^{-4} \mathrm{~m}=1.03 \times 10^{-4} \mathrm{~m}$ This value was used in WVP, $\mathrm{O}_{2} \mathrm{P}$ and $\mathrm{CO}_{2} \mathrm{P}$ calculations.

\subsubsection{Water vapor permeability (WVP)}

The water vapor permeability (WVP) values of the A/C PET and of the five nanolayers were found to be $1.42 \pm 0.39 \times 10^{-11}$ and $0.019 \pm 0.005 \times 10^{-11} \mathrm{~g} \mathrm{~m} /\left(\right.$ Pa s $\left.\mathrm{m}^{2}\right)$, respectively.

In this work, the hydrophobic character of chitosan layers partially explains the lower WVP value of the five layers in comparison with the WVP value of A/C PET. Hydrophobic materials have lower permeability to water vapor because the water molecules have a hydrophilic character, inhibiting the interactions with such materials. On the contrary, there is a stronger affinity between hydrophilic materials and water molecules, favoring their diffusion through the materials' structure. Besides, filaments of pectin can present hydrophobic interactions and hydrogen bonds that originate a three-dimensional solid and amorphous network that retards water migration (Barrera et al., 2002), contributing to the decrease of WVP. Also, the lower WVP value of the five nanolayers is possibly also due to the tightly packed network structure formed by the polymeric matrix, which possibly increases tortuosity and therefore partially restricts the water molecules' transport.

Kokoszka et al. (2010) carried out a study to determine the effect of rapeseed oil on physicochemical properties of whey protein films cast onto Petri dishes. Among several levels of oil concentration and $\mathrm{RH}$ gradients they found that the film thickness decreased from $114.6 \pm 6.6$ without oil to $63.6 \pm 3.3 \mu \mathrm{m}$ with the highest oil concentration (4\%) and the rapeseed oil reduced the water vapor permeability (WVP) of whey protein isolate (WPI) films. Besides, the WVP value ranged between $14.4 \times 10^{-11}$ and $24.2 \times 10^{-11} \mathrm{~g} \mathrm{~m} /\left(\mathrm{Pa} \mathrm{s} \mathrm{m}^{2}\right)$ at $30-53 \% \mathrm{RH}$ gradient and between
$32.2 \times 10^{-11}$ and $74.4 \times 10^{-11} \mathrm{~g} \mathrm{~m} /\left(\right.$ Pa s m$\left.^{2}\right)$ at $30-100 \% \mathrm{RH}$ gradient. They concluded that although the rapeseed oil content affected the WVP of WPI films, particularly at higher humidity values, the RH gradient had an even stronger effect. The question here is that of the influence of a gradient of $\mathrm{RH}$ between the two sides of the films used for WVP measurements. While some authors (e.g. Kokoszka et al., 2010) refer that such gradient may interfere with the results, it is also true that such interference will be higher for thicker films. Since in this work the thickness values are in the nanometer range, such gradients will necessarily be very small (therefore, eventually neglectable).

\subsubsection{Oxygen and carbon dioxide permeabilities}

$\mathrm{O}_{2} \mathrm{P}$ and $\mathrm{CO}_{2} \mathrm{P}$ values for $\mathrm{A} / \mathrm{C}$ PET were found to be $2.5 \pm 0.03 \times$ $10^{-14}$ and $39.7 \pm 22.9 \times 10^{-14} \mathrm{~g} \mathrm{~m} /\left(\right.$ Pa s m$\left.^{2}\right)$, respectively, which were higher or of the same order of magnitude of those determined for the five layers: $0.069 \pm 0.066 \times 10^{-14}$ and $44.8 \pm 32 \times$

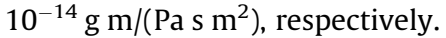

Generally, high $\mathrm{CO}_{2}$ concentrations reduce respiration rates, ethylene production, and induce accumulation of fermentation products of fresh-cut fruits (Gunes et al., 2001; Agar et al., 1999; Gorny et al., 1999), however, excessively high $\mathrm{CO}_{2}$ atmospheres can accelerate tissue browning and necrosis of fruits (Gorny et al., 2002). Further, reduced $\mathrm{O}_{2}$ levels and/or increased $\mathrm{CO}_{2}$ levels have been shown to extend the shelf life of fresh-cut mangoes (Poubol and Izumi, 2005), while Ullah et al. (2010) found that the rate of mangoes' weight loss decreased with an increase of $\mathrm{CO}_{2}$ in the storage atmosphere.

Since the values found for $\mathrm{O}_{2} \mathrm{P}$ and $\mathrm{CO}_{2} \mathrm{P}$ in this work, for the five nanolayers, are lower or of the same order of magnitude of the values of A/C PET and lower than those reported by Cerqueira et al. (2009a) and Souza et al. (2009), working with non-nanoscale coatings of the same materials, and are of the same order of magnitude of the $\mathrm{O}_{2} \mathrm{P}$ determined for a nanolayered coating of $\kappa$-carrageenan and lysozyme $\left(0.10 \pm 0.01 \times 10^{-14} \mathrm{~g} \mathrm{~m} /\left(\mathrm{Pa} \mathrm{s} \mathrm{m}^{2}\right)\right.$ ) (Medeiros et al., in press), these results suggest the selective efficiency of pectin and chitosan-based coating as a barrier to $\mathrm{O}_{2}$ and $\mathrm{CO}_{2}$.

\subsection{Evaluation of coating assembly and mango shelf-life}

\subsubsection{Confirmation of multilayer assembly on mango surface}

The behavior of contact angles values during the progressive coating assembly on mangoes (Fig. 2, on Mango) was found to be similar to those observed with the coating of A/C PET (Fig. 2, on A/C PET).

The contact angle value of $29.70 \pm 5.21^{\circ}$ on mango surface characterizes its hydrophilic character. The character of a surface depends mainly on the nature of its outermost layer but it may occur that such character will still influence the behavior of each coating layer even after the deposition of several layers (Yoo et al., 1998). In the present work, possibly due to the hydrophilic character of mango surface, the magnitude of the contact angles on Pec layers' surface (Layers 1, 3 and 5) of coated mangoes is lower by about $30 \%$ than the corresponding layers on coated A/C PET, ranging from $18.00^{\circ}$ to $20.20^{\circ}$ and showing an increase of hydrophilic character of the surface of these layers. The mango skin has a surface tension of $29.04 \pm 0.02 \mathrm{mN} \mathrm{m}^{-1}$ (Cerqueira et al., 2009b; Souza et al., 2010). The value of the contact angle of the first Pec layer indicates that the Pec solution will easily spread on the mango skin, which has a low surface energy (Choi et al., 2002).

A similar behavior was also found in the magnitude of the contact angles of the surfaces of Ch layers (Layers 2 and 4) applied on coated mangoes; those contact angles were lower by $17 \%$ and $8 \%$, respectively, than those found for coated A/C PET, also exhibiting a slight decrease of hydrophobic character. 
In both cases, however, the trend of contact angle change $(p<0.05)$ when Pec and Ch layers were added on A/C PET and mango was very similar (see Fig. 2), thus clearly indicating that a nanostructure with similar characteristics was being built in either case.

\subsubsection{Quality parameters}

3.2.2.1. Mass loss. Significant differences $(p<0.05)$ were found between uncoated and coated mangoes (Fig. 4 ). On the 45 th day of storage the mass loss was found to be $3.26 \pm 0.25 \%$ and $1.8 \pm$ $0.16 \%$ for uncoated and coated mangoes, respectively. The mass loss comes from transpiration processes (Woods, 1990), which may be increased with increasing temperature and decreasing humidity. It is reasonable to conclude that the differences of mass loss between uncoated and coated mangoes are mainly related to the water vapor barrier provided by the coating.

Souza et al. (2010) worked with a polysaccharide from Anacardium occidentale L. tree gum (Policaju) as a coating for 'Tommy Atkins' mangoes (please note that the experimental period used by these authors was only of $28 \mathrm{~d}$ ) stored at $4{ }^{\circ} \mathrm{C}$ and $82 \%$ $\mathrm{RH}$. They found that a significantly lower mass loss was observed in all mangoes treated with Policaju-based coating. Comparing the results of these authors and the results of this work, it was observed that on the 7 th day of storage, the mangoes coated with Policaju presented a mass loss of $0.30 \%$ while the mangoes coated with the nanolayered coating had a mass loss of $0.52 \%$. The mangoes used in the work of Souza et al. (2010) were acquired in the country of origin (Brazil) and the mangoes used in this work were purchased in Europe, after the mangoes have been subjected to a relatively long shipping period. 'Tommy Atkins' mango is climacteric and ripens rapidly after picking. Disease susceptibility, sensitivity to low storage temperatures (below $13^{\circ} \mathrm{C}$ ), and perishability due to ripening and softening limit the possibility of handling, transport and storage of mango (Baldwin et al., 1999). Changes of temperature may affect the internal atmosphere. Despite the care that has been taken in the purchase and selection of mango at semi-ripe state at a local retail in Europe, certainly the ripening stage was not equal to that of the mango used in Brazil by Souza et al. (2010). Probably all these factors have influenced the magnitude of the mass loss found in this work at the end of the first seven storage days. After the 7th day, the evolution of mass loss was found to be similar in both cases, but ended at the 28th day in the case of Souza et al. (2010) and at the 45th day in the case of the present work. Tefera et al. (2007) worked with the effect of disinfection treatments, packaging, and storage environment on the quality of green mature mangoes (Mangifera indica L.) over a storage period of $28 \mathrm{~d}$. On the 28th day of storage the mass loss of packed mangoes in plastic containers under cool storage, was $26.16 \%$ and $26.38 \%$ for the mangoes subjected to disinfection treatments of $5 \% \mathrm{NaOCl}$ and $\mathrm{H}_{2} \mathrm{O}\left(\right.$ at $46^{\circ} \mathrm{C}$ ), respectively.

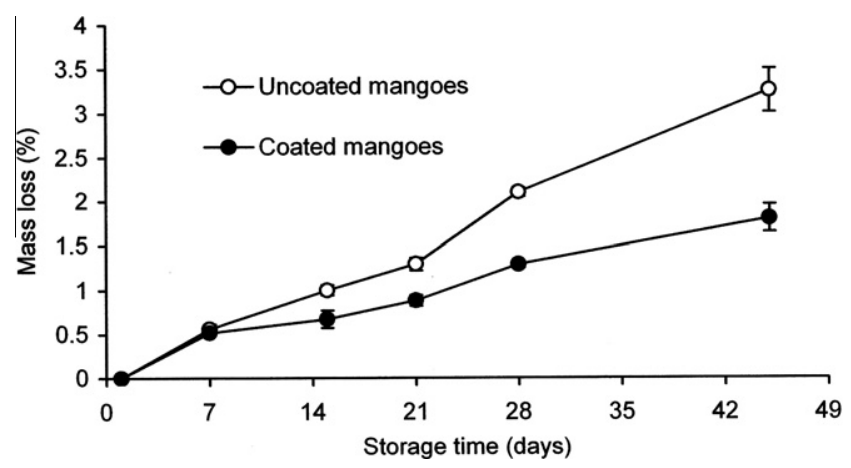

Fig. 4. Mass loss of mangoes during $45 \mathrm{~d}$ of storage. Each data point is the average of three determinations and the error bars show the standard deviation.
3.2.2.2. Total soluble solids (TSS). Normally, total soluble solids (TSS) content increases during the ripening due to the degradation of polysaccharides present in the fruit. There is also an increase of TSS when the water loss increases leading to the increase of sugar concentrations in the fruit tissues. The reduction of $\mathrm{O}_{2}$ concentration affects the respiration process thus causing a decrease in the ethylene production and consequently extending the ripening period (Gorris and Peppelenbos, 1992). The TSS of uncoated mangoes significantly $(p<0.05)$ increased during the experimental period until the 28 th day, from $11.5 \pm 0.3^{\circ}$ to $17.63 \pm 0.4{ }^{\circ} \mathrm{Brix}$, and decreased slightly on the 45 th day of storage to $15.8 \pm 0.3^{\circ} \mathrm{Brix}$. The TSS of coated mangoes remained relatively stable during the total experimental period, from $11.5 \pm 0.05^{\circ}$ to $13.3 \pm 0.1^{\circ}$ Brix (Fig. 5). These results suggest the efficacy of the coating as a gas barrier, possibly slowing down the metabolism due to the lesser amount of $\mathrm{O}_{2}$ available.

3.2.2.3. Titratable acidity (TA). Another parameter that varies with the ripening process is the titratable acidity (TA), due to the organic acids that are usually consumed during the ripening and after picking. The titratable acidity (TA) of uncoated and coated mangoes were $0.77 \pm 0.3(\%)$ and $0.80 \pm 0.01(\%)(p>0.05)$, respectively, at the beginning of the experimental period, and decreased until the 45 th day of storage to significantly different values $(p<0.05)$ of $0.12 \pm 0.01(\%)$ and $0.40 \pm 0.01$ (\%), respectively (Fig. 6 ). The higher TA values of coated mangoes are probably due to the slowdown of the respiration process in the presence of the reduced amounts of $\mathrm{O}_{2}$ provided by the coating.

3.2.2.4. Latest findings. There are several publications on the conservation of fruit after picking. Generally, those works focus on the conditions of packaging and storage, or on packaging materials;

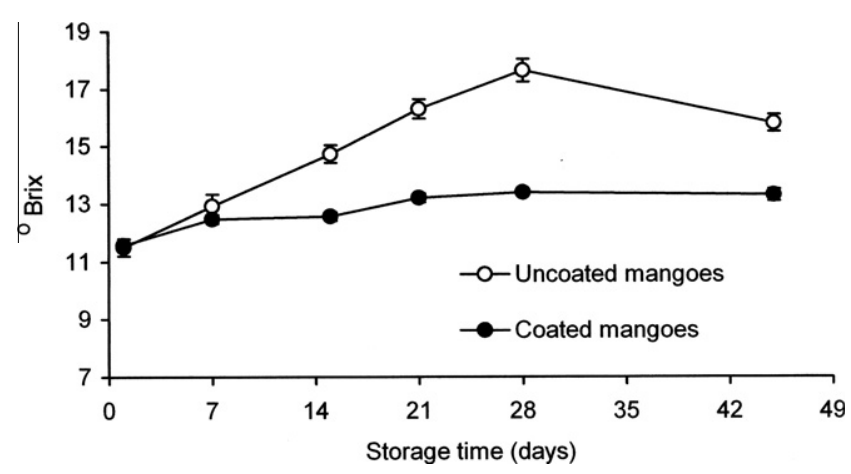

Fig. 5. Total soluble solids (TSS) of mangoes during $45 \mathrm{~d}$ of storage. Each data point is the average of three determinations and the error bars show the standard deviation.

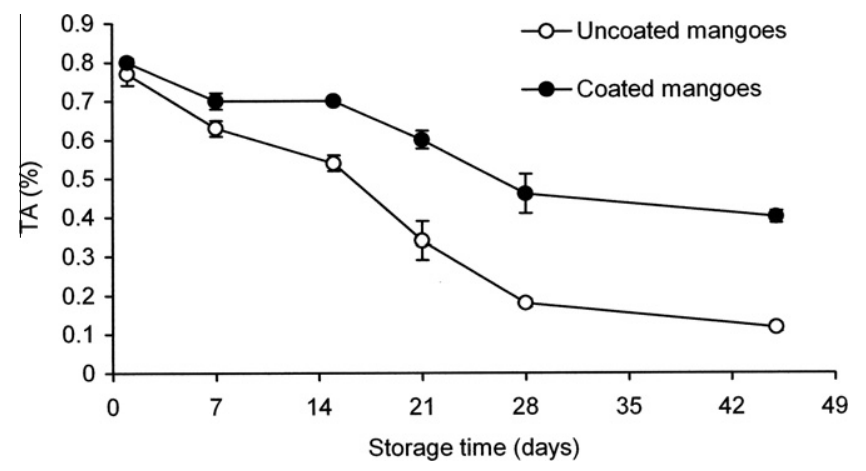

Fig. 6. Titratable acidity (TA) of mangoes during $45 \mathrm{~d}$ of storage. Each data point is the average of three determinations and the error bars show the standard deviation. 

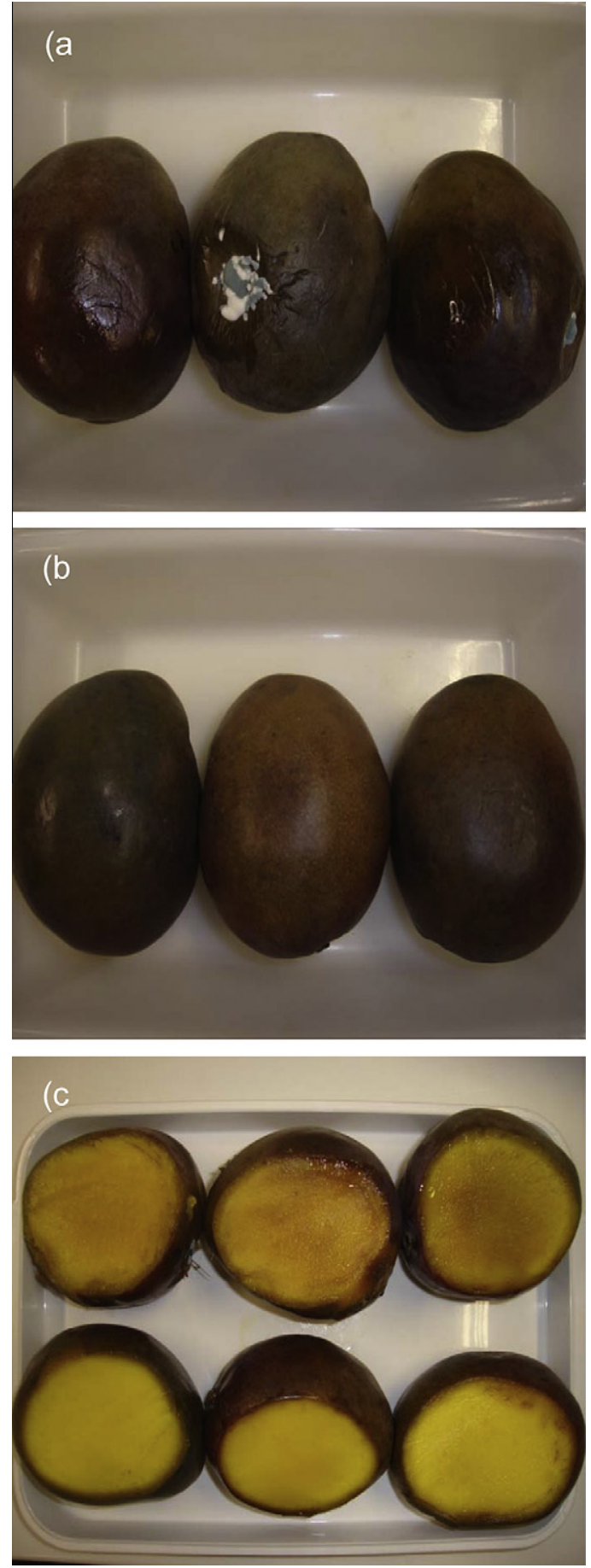

Fig. 7. Mangoes on the 45th day of storage. (a) Uncoated mangoes; (b) coated mangoes; (c) appearance of mangoes flesh exposed by a longitudinal cut of the uncoated mangoes (three samples above) and of the coated mangoes (three samples below).

however, only a restrict number involve coatings, and often their results cannot be compared. To our knowledge, only a residual number of works involving nanocoatings for food applications were published. After picking, the life of mango is limited by physiological deterioration from excessive fruit ripening that causes decay and simultaneously creates the conditions for the development of microbial spoilage, causing the rotting of the fruit. The water loss may reach levels that cause wrinkling and shriveling of man- goes and commit to their appearance and decrease its commercial value (Pfaffenbach et al., 2003).

On the 45th day of storage the uncoated mangoes exhibited in Fig. 7a had a wrinkled damaged appearance, and microbiological spoilage effects were visible, in comparison with the coated mangoes of Fig. 7b where none of these were observed. Several chemical side groups appear to interact with water molecules via hydrogen bonds. For instance, the ester groups present in pectin (which is part of the nanocoating structure) are known to be good acceptors of hydrogen bonds and can thus trap water molecules in proximity to the polymer (Crouzier et al., 2010). This is possibly the reason why, at the end of experimental period, the surface of coated mangoes exhibited in Fig. 7b was found to be less dehydrated. The mango flesh of uncoated mangoes had a dark yellow color while the flesh of coated mangoes had a uniform light yellow color as presented in Fig. 7c. When evaluating the chemical alterations in 'Tommy Atkins' mangoes, Lima et al. (2010) observed that at the end of the ripening period, the fruits showed a reduction of the amount of total carotenoids which can be related with the oxidation reactions of pigments or phenolic compounds, causing the darkening of mango flesh. Lee et al. (1993) reported the darkening of the flesh of caquis due to the oxidation of phenolic compounds, when the fruits were stored under a high $\mathrm{O}_{2}$ concentration. The results achieved in this work suggest that the pectin and chitosanbased coating used here provided a good $\mathrm{O}_{2}$ barrier, as suggested by the values of $\mathrm{O}_{2} \mathrm{P}$.

\section{Conclusion}

A nanomultilayer coating system based on food-grade materials has been developed and characterized. The values that were found for WVP, $\mathrm{O}_{2} \mathrm{P}$ and $\mathrm{CO}_{2} \mathrm{P}$ were $0.019 \pm 0.005 \times 10^{-11} \mathrm{~g} \mathrm{~m} /\left(\mathrm{Pa} \mathrm{s} \mathrm{m}{ }^{2}\right)$, $0.069 \pm 0.066 \times 10^{-14} \pm \mathrm{g} \mathrm{m} /\left(\right.$ Pa s m$\left.^{2}\right)$ and $44.8 \pm 32 \times 10^{-14} \mathrm{~g} \mathrm{~m} /$ $\left(\mathrm{Pa} \mathrm{s} \mathrm{m}^{2}\right)$, respectively, are all in the same order of magnitude of other coatings reported in the literature with efficiency in the reduction of gas flow.

This system's functionalities as a possible alternative to conventional food coatings were preliminarily tested on mangoes. Clearly, coated mangoes performed better than uncoated mangoes. Uncoated mangoes presented a higher mass loss, higher total soluble solids (TSS) and a lower titratable acidity (TA) in comparison with coated mangoes. After $45 \mathrm{~d}$ of storage, coated mangoes presented a better external appearance, a less dehydrated surface, apparently without fungal growth, and a much more preserved flesh.

These findings suggest that the combination of the antimicrobial and gas barrier properties of chitosan, with the low oxygen permeability of pectin layers were possibly efficient in the reduction of gas flow and on the extension of the shelf-life of mangoes. Barrier properties were possibly improved by the nano-structure of the coating (e.g. by improving the tortuosity of the polymer network and/or by imposing successive interfaces to the gas molecules while migrating through the structure), but this remains to be demonstrated.

\section{Acknowledgments}

The author Bartolomeu G.S. Medeiros was recipient of a scholarship from de Project Isac (Isac Mundus Cooperation, European Union) and is also a recipient of a scholarship from Coordenação de Aperfeiçoamento de Pessoal de Nível Superior (Capes, Brazil). The author Ana C. Pinheiro is recipient of a fellowship (SFRH/BD/ 48120/2008) from the Fundação para a Ciência e Tecnologia (FCT, Portugal). The present work was supported by CAPES/PROCAD/ $\mathrm{NF} / 1415 / 2007$ 


\section{References}

Agar, I.T., Massantini, R., Hess-Pierce, B., Kader, A.A., 1999. Postharvest $\mathrm{CO}_{2}$ and ethylene production and quality maintenance of fresh-cut kiwifruit slices. Journal of Food Science 64, 433-440.

ASTM D 3985-02, 2002. Standard test method for oxygen gas transmission rate through plastic film and sheeting using a coulometric sensor. In: ASTM Book of Standards, 15.09.

Baldwin, E.A., Burns, J.K., Kazokas, W., Brecht, J.K., Hagenmaier, R.D., Bender, R.J., Pesis, E., 1999. Effect of two edible coatings with different permeability characteristic on mango (Mangifera indica L.) ripening during storage. Postharvest Biology and Technology 17, 215-226.

Barrera, A.M., Ramírez, J.A., González-Cabriales, J.J., Vázquez, M., 2002. Effect of pectins on the gelling properties of surimi from silver carp. Food Hydrocolloids $16,441-447$.

Carneiro-da-Cunha, M.G., Cerqueira, M.A., Souza, B.W.S., Carvalho, S., Quintas, M.A.C., Teixeira, J.A., Vicente, A.A., 2010. Physical and thermal properties of a chitosan/alginate nanolayered PET film. Carbohydrate Polymers 82 (1), 153159

Cerqueira, M.A., Lima, A.M., Souza, B.W.S., Teixeira, J.A., Moreira, R.A., Vicente, A. 2009a. Functional polysaccharides as edible coatings for cheese. Journal of Agricultural and Food Chemistry 57, 1456-1462.

Cerqueira, M.A., Lima, A.M., Teixeira, J.A., Moreira, R.A., Vicente, A.A., 2009b. Suitability of novel galactomannans as edible coatins for tropical fuits. Journal of Food Engineering 94, 372-378.

Chien, P., Sheu, F., Yang, F., 2007. Effects of edible chitosan coating on quality and shelf- life of sliced mango fruit. Journal of Food Engineering 78, 225-229.

Choi, W.Y., Park, H.J., Ahn, D.J., Lee, J., Lee, C.Y., 2002. Wettability of chitosan coating solution on Fujiapple skin. Journal of Food Science 67 (7), 2668-2672.

Crouzier, T., Boudou, T., Picart, C., 2010. Polysaccharide-based polyelectrolyte multilayers. Current Opinion in Colloid and Interface Science 15, 417-426.

Elsabee, M.Z., Abdou, E.S., Nagy, K.S.A., Eweis, M., 2008. Surface modification of polypropylene films by chitosan and chitosan/pectin multilayer. Carbohydrate Polymers 71, 187-195.

Evangelista, R.M., Chitarra, A.B., Chitarra, M.I.F., 2002. Ultrastructural changes in the cell wall of mango 'Tommy Atkins' treated with calcium chloride at pré-harvest time. Revista Brasileira de Fruticultura 24 (1), 254-257.

Fonseca, M.J.O., 1999. Efeito de fungicidas e cera na conservação pós-colheita de manga (Mangifera indica L.) "Tommy Aktins". Revista Brasileira de Fruticultura 27, 21-24.

Fu, J., Ji, J., Yuan, W., Shen, J., 2005. Construction of anti-adhesive and antibacterial multilayer assembly of heparin and chitosan. Biomaterials 26, 6684-6692.

Gorny, J.R., Hess-Pierce, B., Kader, A.A., 1999. Quality changes in fresh-cut peach and nectarine slices as affected by cultivar, storage atmosphere and chemical treatments. Journal of Food Science 64, 429-432.

Gorny, J.R., Hess-Pierce, B., Cifuentes, R.A., Kader, A.A., 2002. Quality changes in fresh-cut pear slices as affected by controlled atmospheres and chemical preservatives. Postharvest Biology and Technology 24, 271-278.

Gorris, L.G.M., Peppelenbos, H.W., 1992. Modified atmosphere and vacuum packaging to extend the shelf-life of respiring food products. HortTechnology 2, 303-309.

Gunes, G., Watkins, C.B., Hotchkiss, J.H., 2001. Physiological responses of fresh-cut apple slices under high $\mathrm{CO} 2$ and low $\mathrm{O} 2$ partial pressures. Postharvest Biology and Technology 22, 197-204.

Instituto Adolfo Lutz, 1985. Normas Analíticas: Métodos químicos e físicos para análises de alimentos, vol. 1, third ed. São Paulo, Brazil, 533pp.

Kokoszka, S., Debeaufort, F., Lenart, A., Voilley, A., 2010. Liquid and vapour water transfer through whey protein/lipid emulsion films. Journal of the Science of Food and Agriculture 90, 1673-1680.

Kumar, M.N.V.R., Muzzarelli, R.A.A., Muzzarelli, C., Sashiwa, H., Domb, A.J., 2004. Chitosan Chemistry and Pharmaceutical Perspectives. Chemical Reviews 104, 6017-6084.

Lee, S.K., Shin, I.S., Park, Y.M., 1993. Factors involved in skin browning of nonastringent 'Fuyu' persimmon. Acta Horticulturae 37 (3), 300-303.

Lima, A.M., Cerqueira, M.A., Souza, B.W.S., Santos, E.C.M., Teixeira, J.A., Moreira, R.A., Vicente, A.A., 2010. New edible coatings composed of galactomannans and collagen blends to improve the postharvest quality of fruits - influence on fruits gas transfer rate. Journal of Food Engineering 97, 101-109.

Marudova, M., Lang, S., Brownsey, G.J., Ring, S.G., 2005. Pectin-Chitosan multilayer formation. Carbohydrate Research 340, 2144-2149.

McHugh, T.H., Avena-Bustillos, R.J., Krochta, J.M., 1993. Hydrophilic edible film: modified procedure for water vapour permeability and explanation of thickness effects. Journal Food Science 58, 899-903.

Medeiros, B.G., Pinheiro, A.C., Teixeira, J.A., Vicente, A.A., Carneiro-da-Cunha, M.G., in press. Polysaccharide/protein nanomultilayer coatings: construction, characterization and evaluation of their effect on 'Rocha' pear (Pyrus communis L.) shelf-life. Food and Bioprocess Technology. doi:10.1007/s11947010-0508-0.

Morra, M., Cassinelli, C., 1996. Staphylococcus epidermidis adhesion to films deposited from hydroxyethylmethacrylate plasma. Journal of Biomedical Material Research 31, 149-155.

Newman, A.W., Kwok, D.Y., 1999. Contact angle measurement and contact angle interpretation. Advances in Colloid and Interface Science 81, 167-249.
Nisperos-Carriedo, M., 1994. Edible coatings and films based on polysaccharides. In: Krochta, J., Baldwin, E., Nisperos-Carriedo, M. (Eds.), Edible Coatings and Films to Improve Food Quality. Technomic Publishing Company.

Nunthanid, J., Laugtana-anan, M., Sriamornsak, P., Limmatvapirat, S., Huanbutta, K., Puttipipatkhachorn, S., 2009. Use of spray-dried chitosan acetate and ethylcellulose as compression coats for colonic drug delivery: effect of swelling on triggering in vitro drug release. European Journal of Pharmaceutics and Biopharmaceutics 71, 356-361.

Olivas, G.I., Barbosa-Cánovas, G.V., 2005. Edible coatings for fresh-cut fruits. Critical Reviews in Food Science and Nutrition 45, 657-670.

Park, S.I., Zhao, Y., 2004. Incorporation of a high concentration of mineral or vitamin into chitosan-based films. Journal of Agricultural and Food Chemistry 52 (7), 1933-1939.

Pfaffenbach, L.B., Castro, J.V., Carvalho, C.R.L., Rossetto, C.J., 2003. The effect of modified atmosphere and refrigeration on post-harvest of mango red espada. Revista Brasileira de Fruticultura 25 (3), 410-413.

Poubol, J., Izumi, H., 2005. Shelf life and microbial quality of fresh-cut mango cubes stored in high $\mathrm{CO}_{2}$ atmospheres. Journal of Food Science 70 (1), 69-74.

Ravindra, M.R., Goswami, T.K., 2008. Modelling the respiration rate of green mature mango under aerobic conditions. Biosystems Engineering 99, 239-248.

Ribeiro, C., Vicente, A.A., Teixeira, J.A., Miranda, C., 2007. Optimization of edible coating composition to retard strawberry fruit senescence. Postharvest Biology and Technology 44, 63-70.

Rojas-Grau, M.A., Tapia, M.S., Martín-Belloso, O., 2008. Using polysaccharide-based edible coatings to maintain quality of fresh-cut Fuji apples. LWT-Food Science and Technology 41, 139-147.

Shumilina, E.V., Shchipunov, Y.A., 2002. Chitosan-carrageenan gels. Colloid Journal 64 (3), 372-378.

Souza, B.W.S., Cerqueira, M.A., Casariego, A., Lima, A.M.P., Teixeira, J.A., Vicente, A.A., 2009. Effect of moderate electric fields in the permeation properties of chitosan coatings. Food Hydrocolloids 23, 2110-2115.

Souza, M.P., Cerqueira, M.A., Souza, B.W.S., Teixeira, J.A., Porto, A.L.F., Vicente, A.A., Carneiro-da-cunha, M.G., 2010. Polysaccharide from Anacardium occidentale L. tree gum (Policaju) as a coating for Tommy Atkins mangoes. Chemical Papers 64 (4), 475-481.

Sriamornsak, P., Thirawong, N., Weerapol, Y., Nunthanid, J., Sungthongjeen, S., 2007. Swelling and erosion of pectin matrix tablets and their impact on drug release behavior. European Journal of Pharmaceutics and Biopharmaceutics 67, 211219.

Srinivasa, P.C., Baskaran, R., Ramesh, M.N., Prashanth, K.H., Tharanathan, R., 2002 Storage studies of mango packed using biodegradable chitosan film. European Food Research and Technology 215 (6), 504-508.

Strand, S.P., Tomeras, K., Varum, K.M., Ostgaard, K., 2001. Electrophoretic light scattering studies of chitosans with different degrees of $\mathrm{N}$-acetylation. Biomacromolecules 2 (4), 1310-1340.

Suyatma, N.E., Tighzert, L., Copinet, A., 2005. Effects of hydrophilic plasticizers on mechanical, thermal, and surface properties of chitosan films. Journal of Agricultural and Food Chemistry 53 (10), 3950-3957.

Tefera, A., Seyoum, T., Woldetsadik, K., 2007. Effect of disinfection, packaging, and storage environment on the shelf-life of mango. Biosystems Engineering 96 (2), 201-212.

Thumula, P., 2006. Study on storage of tomatoes coatin behavior of lysozymechitosan films. M.Sc. Thesis, Department of Biouresource Engineering, Faculty Agricultural and Environmental Sciences McGillUniversity, Montreal, Quebec, Canada.

Tripathi, S., Mehrotra, G.K., Dutta, P.K., 2008. Chitosan based antimicrobial films for food packaging applications. E-Polymers 093, 1-7.

Ullah, H., Ahmad, S., Thompson, A.K., Anwar, R., Menon, N.-U.-N., Nafees, M. 2010. Effect of "Oxygen and Carbon-dioxide" on the pot-harvest management in tree-ripe mango storage. Journal of Chemical Society of Pakistan 32 (4), 485-491.

Westall, S., Filtenborg, O., 1998. Spoilage yeasts of decorated soft cheese packed in modified atmosphere. Food Microbiology 15, 243-249.

Woods, J.L., 1990. Moisture loss from fruits and vegetables. Postharvest News and Information 1 (3), 195-199.

Wu, T., Zivanovic, S., Draughon, F.A., Conway, W.S., Sams, C.E., 2005. Physicochemical properties and bioactivity of fungal chitin and chitosan. Journal of Agricultural and Food Chemistry 53 (10), 3888-3894.

Xu, J.-P., Wang, X.-L., Fan, De.-Z., Ji, J., Shen, J.-C., 2008. Construction of phospholipid anti-biofouling multilayer on biomedical PET surfaces. Applied Surface Science 255, 538-540.

Yoo, D., Shiratori, S.S., Rubner, M.F., 1998. Controlling bilayer composition and surface wettability of sequentially adsorbed multilayers of weak polyelectrolytes. Macromolecules 31 (13), 4309-4318.

Zhang, D., Quantick, P., 1997. Effects of chitosan coatings on enzymatic browning and decay during postharvest storage of litchi (Litchi chinensis Sonn.) fruit. Postharvest Biology Technology 12, 195-202.

Zhu, Y., Gao, C., He, T., Shen, J., 2004. Endothelium regeneration on luminal surface of polyurethane vascular scaffold modified with diamine and covalently grafted with gelatin. Biomaterials 25, 423-430.

Zsivánovits, G., Marudova, M., Ring, S., 2005. Influence of mechanical properties of pectin films on charge density and charge density distribution in pectin macromolecule. Colloid and Polymer Science 284, 301-308. 